\title{
Standard dilution analysis in flow system: Sodium determination by flame atomic emission spectrometry
}

\author{
Felipe M. Fortunato ${ }^{a}$, Marcos A. Bechlin ${ }^{a}$, José A. Gomes Neto ${ }^{\mathrm{a}, *}$, Alex Virgilio ${ }^{\mathrm{b}}$, \\ George L. Donati ${ }^{c}$, Bradley T. Jones ${ }^{c}$ \\ a UNESP - Univ. Estadual Paulista, Instituto de Química, P.O. Box 355, 14800-060, Araraquara, São Paulo, Brazil

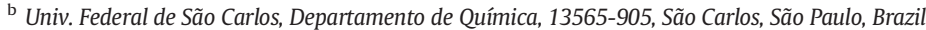 \\ c Wake Forest University, Department of Chemistry, Salem Hall Box 7486, Winston-Salem, NC 27109, USA
}

\section{A R T I C L E I N F O}

\section{Article history:}

Received 1 October 2015

Accepted 8 October 2015

Available online 21 October 2015

\section{Keywords:}

Standard dilution analysis

Flow-injection analysis

Calibration

\begin{abstract}
A B S T R A C T
Standard dilution analysis (SDA) is a new calibration method that combines the principles of internal standardization and standard additions. The current work evaluated the feasibility of SDA automation using a flow-injection system (FIA). The FIA-SDA system was applied to sodium determination in biodiesel samples and certified reference materials (CRMs) by flame atomic emission spectrometry (FAES). Lithium was employed as internal standard in all determinations. The results for Na determination in five CRMs using FIA-SDA were in agreement with certified values at the $95 \%$ confidence level ( $t$-test). For comparison purposes, Na was also determined by the traditional methods of external standard (ES), standard additions (SA) and internal standardization (IS). Recoveries showed increased accuracy following the sequence ES $(181-202 \%)<$ IS $(67-72 \%)<$ SA $(111-126 \%)<$ FIA-SDA (94-98\%). FIA-SDA provided more accurate and precise results than ES, SA and IS for Na determination in biodiesel and CRMs by FAES.
\end{abstract}

(C) 2015 Elsevier B.V. All rights reserved.

\section{Introduction}

In analytical chemistry, instrumental methods generally require careful calibration for determining the concentration of an analyte in an unknown sample [1,2]. External standard calibration (ES) is the most commonly used calibration method due its simplicity of application and interpretation [3]. However, this method is susceptible to errors mainly caused by variations in instrumental parameters and/or matrix effects which can deteriorate precision and/or accuracy. These drawbacks can be circumvented by using other types of calibration such as matrix matching, standard addition (SA) and internal standardization (IS) [4-6].

A novel calibration method called standard dilution analysis (SDA), that combines the principles of the traditional methods of SA and IS was recently proposed in the literature [7]. It can be performed by providing the detector with a solution containing a constant amount of sample and a varying amount of standard solution containing both analyte and internal standard. SDA was applied for the determination of FD\&C dye Blue No. 1 in mouthwash by spectrophotometry, and $\mathrm{Al}, \mathrm{Cd}$, $\mathrm{Co}, \mathrm{Cr}, \mathrm{Cu}, \mathrm{Fe}, \mathrm{Ni}$ and $\mathrm{Pb}$ in water, nitric acid, mouthwash, wine, and cola by inductively coupled plasma optical emission spectrometry (ICP OES). The procedure was based on manually combining two solutions (e.g. A and B). Solution A, containing 50\% sample and 50\% standard

\footnotetext{
* Corresponding author. Tel.: + 551633019611.

E-mail address: anchieta@iq.unesp.br (J.A. Gomes Neto).
}

mixture (analyte plus internal standard), is mixed with solution B, which contains the sample and the blank. After mixing the two solutions (by pouring solution B into the same tube containing solution A), many calibration points are generated on-the-fly as solution $A$ is diluted by solution $B$. In this case, only the standard solution is in fact diluted and the sample matrix never changes (both solutions $A$ and $B$ have $50 \%$ sample), which results in an efficient matrix-matching procedure. Details on the mathematical approach for calculating the concentration of analyte in SDA determinations are described elsewhere [7]. Despite its efficiency and relatively high sample throughput, the SDA method is all manual. The analyst must pay close attention to the different phases of signal acquisition (i.e., introduction of solution $\mathrm{A}$, gradient zone, and after solutions A and B are completely mixed) in order to ensure enough data points for calibration. The automation of the SDA method is therefore an interesting approach to minimize errors and further improve sample throughput, since time and conditions of solution mixing can be made highly reproducible.

Considering that flow-injection analysis (FIA) is an excellent technique to manage solutions [8], the present work reports on the development of a combined automated FIA-SDA system for real sample applications. The method is applied to sodium determination in biodiesel samples and certified reference materials (CRMs) of milk, biological tissues and biodiesel by flame atomic emission spectrometry (FAES) employing Li as internal standard [2,9]. The efficiency of the FIA-SDA system is also checked by comparing its results with values obtained with the traditional methods of ES, SA and IS. 


\section{Materials and methods}

\subsection{Reagents, analytical solutions and samples}

High purity deionized water obtained using a Millipore Rios $5 \circledR$ reverse osmosis and a Millipore Milli- $\mathrm{Q}^{\mathrm{TM}}$ Academic $\AA$ deionizer system (resistivity $18.2 \mathrm{M} \Omega \mathrm{cm}$, Millipore, Bedford, USA) was used to prepare all solutions.

Analytical solutions were prepared by appropriate dilution of $1000 \mathrm{mg} \mathrm{L}^{-1} \mathrm{Na}$ and Li stock solutions (SpecSol, São Paulo, Brazil). Distilled ethanol was used for biodiesel samples dilution. Nitric acid 70\% (JT Baker, Phillipsburg, USA) and $\mathrm{H}_{2} \mathrm{O}_{2} 30 \% \mathrm{v} \mathrm{v}^{-1}$ (Merck, Darmstadt, Germany) were used for CRMs digestion.

All solutions were stored in high-density polypropylene flasks (Nalgene, Rochester, USA). All plastic containers and glassware materials were decontaminated by soaking in $10 \%\left(\mathrm{v} \mathrm{v}^{-1}\right) \mathrm{HNO}_{3}$ for at least $24 \mathrm{~h}$, and then rinsing abundantly in deionized water before use.

Biodiesel samples provided by the Monitoring and Research Center of Fuel Quality, Biofuels, Oil and Derivatives (CEMPEQC, Araraquara, Brazil) were stored in amber glass flasks in a refrigerator (about $5{ }^{\circ} \mathrm{C}$ ) before analysis. A mass of $2.0 \mathrm{~g}$ biodiesel samples and $2.0 \mathrm{~g}$ biodiesel standard oil (Conostan, Baie-D'Urfé, Canada) were directly weighed into 15-mL polypropylene graduated flasks (Corning, New York, USA) and the volumes were made up to $10 \mathrm{~mL}$ with distilled ethanol $[10,11]$.

All CRMs (1549 Non-Fat Milk Powder, 8435 Whole Milk Powder, 1577b Bovine Liver, and 2976 Mussel Tissue) from the National Institute of Standards and Technology (Gaithersburg, USA) were prepared by microwave-assisted wet digestion. Sample masses of $\mathrm{ca} .200 \mathrm{mg}$ were accurately weighed and transferred to microwave flasks followed by $3.0 \mathrm{~mL} \mathrm{HNO}_{3}, 1.0 \mathrm{~mL} \mathrm{H}_{2} \mathrm{O}_{2}$ and $2.0 \mathrm{~mL}$ of deionized water. Then, the mixtures were heated using the following five-step microwave program: (1) $15 \mathrm{~min}$ from 0 to $600 \mathrm{~W}$; (2) $5 \mathrm{~min}$ at $600 \mathrm{~W}$; (3) $15 \mathrm{~min}$ from 600 to $800 \mathrm{~W}$; (4) $5 \mathrm{~min}$ at $800 \mathrm{~W}$ and (5) $20 \mathrm{~min}$ at $0 \mathrm{~W}$ (cooling). After cooling, the digests were transferred to $25 \mathrm{~mL}$ volumetric flasks and diluted to the mark with deionized water.

\subsection{Instrumentation}

An Analyst 100 Perkin Elmer flame atomic absorption spectrometer (Shelton, USA) equipped with a 50 -mm burner head was used for sample nebulization and analyte excitation. An air-acetylene flame was employed for $\mathrm{Na}$ and $\mathrm{Li}$ excitation. The optimum air-acetylene flow- rates for $\mathrm{Na}$ and Li excitation was a 4:2 (air:acetylene) ratio. Acetylene with 99.7\% purity (Air Liquid, São Paulo, Brazil) was used as fuel gas.

The emission intensities from $\mathrm{Na}$ and $\mathrm{Li}$ were measured at $586.98 \mathrm{~nm}$ and $667.43 \mathrm{~nm}$, respectively, using an USB 650 Red Tide Ocean Optics spectrometer (Dunedin, FL, USA). The acquisition of emission signals by the Ocean Optics spectrometer (SpetraSuite software) employed a 50-ms integration time in high-speed mode (6000 spectra recorded by each analytical cycle).

An IPC-8 Ismatec peristaltic pump (Zurich, Switzerland) furnished with Tygon ${ }^{\circledR}$ tubes was used for pumping solutions.

A Multiwave 3000 Anton Paar (Graz, Austria) microwave oven with a rotor of 48 reaction PFA vessels (internal volume of $50 \mathrm{~mL}$ ) was used to digest all CRMs.

\subsection{The flow system}

The FIA-SDA system comprised a peristaltic pump, Tygon ${ }^{\circledR}$ pumping tubes, a manual injector-commutator [12], a flame atomizer, a fiberoptic spectrophotometer, polyethylene tubing (i.d. $0.8 \mathrm{~mm}$ ), coiled reactor and accessories. The flow diagram of the simultaneous $\mathrm{Na}$ and $\mathrm{Li}$ signal acquisition system is shown in Fig. 1. The operation of the injector-commutator IC involves the sequential introduction of solutions $A$ and $B$ in the system. In the position specified in the figure, an aliquot of solution $A\left(S_{A}\right)$ selected by the loop $L_{1}$ is injected into the water carrier stream $(\mathrm{C})$. The established sample zone reaches the atomizer and a steady-state emission signal is measured. After $150 \mathrm{~s}$, the IC is switched and the solution $B\left(S_{B}\right)$ selected by the loop $L_{2}$ is injected into the carrier $\mathrm{C}$. Passage of the sample zone through the flame results in a steady-state signal. After baseline restoration, another cycle can be started. A typical signal profile obtained with the proposed flow system is depicted in Fig. 2.

\subsection{Analytical procedure}

The SDA method [7] requires just a blank and two analytical solutions ( $A$ and $B$ ) for each sample. Solution $A$ is a mixture of standards (analyte plus internal standard) and sample (1:1 ratio by volume), and solution $B$ is a mixture of sample and blank solutions ( $1: 1$ ratio by volume). The solutions must be simultaneously measured in order to obtain a typical SDA graph [7]. Considering the flow system in Fig. 1, the injected sample volume (length of the sampling loops) and the length of reactor coil were evaluated to ensure well-defined steady-state

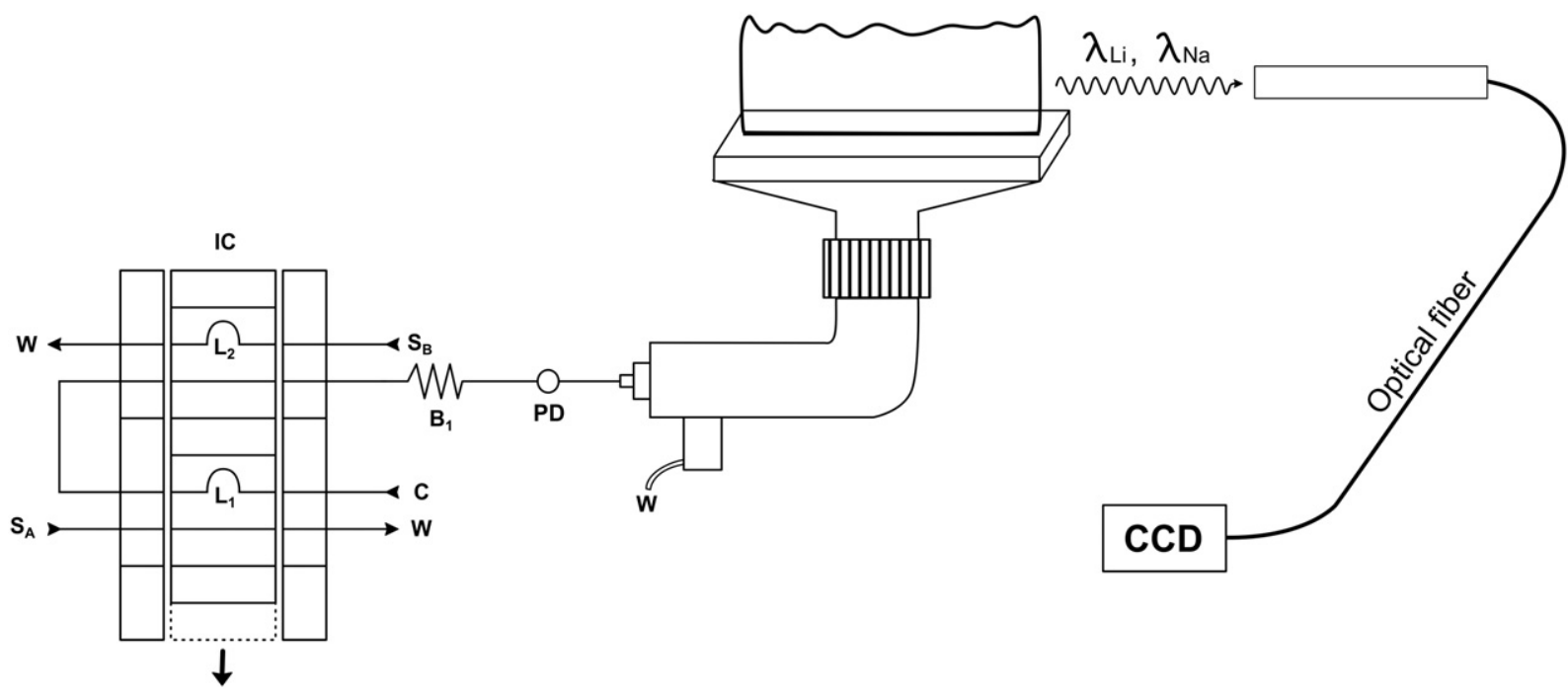

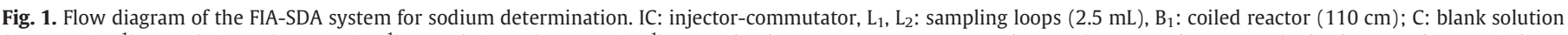

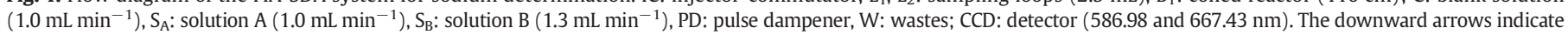
the movement of the central part of IC. 


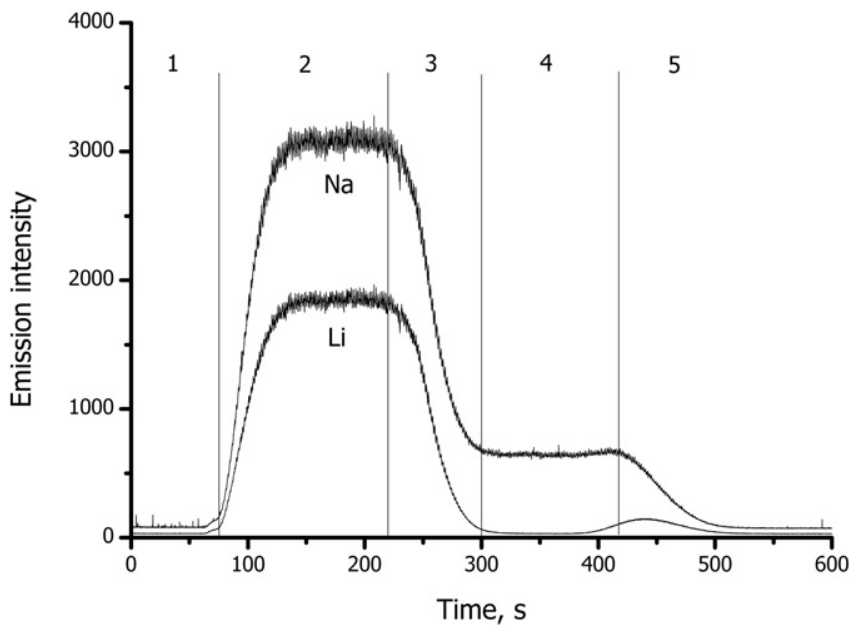

Fig. 2. Typical transient signals for $\mathrm{Na}$ and Li measured by the FIA-SDA system. Regions \# 1,2,3,4 and 5 delimited by vertical lines correspond to the blank, solution A, SDA region, solution B and blank, respectively.

signals for $\mathrm{S}_{\mathrm{A}}$ and $\mathrm{S}_{\mathrm{B}}$, and a definite transition curve (SDA region) between them. In this study, solutions $S_{A}$ and $S_{B}$ were prepared by using $0.5 \mathrm{mg} \mathrm{L}^{-1} \mathrm{Na}$ as sample solution, a standard solution containing $1.0 \mathrm{mg} \mathrm{L}^{-1} \mathrm{Na}+1.0 \mathrm{mg} \mathrm{L}^{-1} \mathrm{Li}$ and deionized water as blank.

The SDA method requires the simultaneous collection of emission intensities of $\mathrm{Na}\left(\mathrm{I}_{\mathrm{Na}}\right)$ and $\mathrm{Li}\left(\mathrm{I}_{\mathrm{Li}}\right)$ at the transitional curve between steady-state regions (SDA curve), and the corresponding Li concentrations. Signal intensities and internal standard concentration $\left(\mathrm{C}_{\mathrm{IS}}\right)$ are employed to build SDA plots $\left(\mathrm{I}_{\mathrm{Na}} / \mathrm{I}_{\mathrm{Li}}\right.$ versus $\left.1 /[\mathrm{Li}]\right)$ from which analyte concentration in the sample $\left(\mathrm{C}^{\mathrm{sam}}\right)$ is calculated by using the following equation $\mathrm{C}^{\text {sam }}=($ slope/intercept $) \times\left(C_{\text {std }} / C_{I S}\right)$, where $C_{\text {std }}$ and $C_{I S}$ are standard and internal standard concentrations in the originally prepared standard solution, respectively [7]. Lithium concentration was calculated at different points of the SDA region by linear interpolation of Li emission intensities within the baseline (zero concentration) and steady state signal (known Li concentration).

Considering the excessive number of spectra for calibration, the use of a set of 10, 20, 30, 40 and 50 points to generate an average spectrum was evaluated.

The influence of data acquisition at different sub-regions of the SDA region on accuracy was evaluated. Different sub-regions were selected in order to cover emission intensities from the steady-state $(100 \%$ intensity) to baseline (0\% intensity) interval: $100-0 \%$; $90-10 \%$; $90-0 \%$; $100-10 \%$.

Determinations of $\mathrm{Na}$ in samples and CRMs by using comparative calibrations (ES, SA and IS) were performed in seven replicates in batch mode. The aspiration rate of the flame spectrometer was fixed to $5.0 \mathrm{~mL} \mathrm{~min}^{-1}$.

\subsection{Sodium determination}

After system optimization, the method was applied to the determination of Na in five biodiesel samples. Accuracy was checked by analyzing different CRMs. The performance of the procedure was also evaluated by comparing the FIA-SDA results with values obtained with ES, SA and IS.

The proposed procedure involves the preparation of two solutions (A and B) for biodiesel analysis: $50 \%$ sample solution $+50 \%$ standard (1.0 mg L ${ }^{-1} \mathrm{Li}+1.0 \mathrm{mg} \mathrm{L}^{-1} \mathrm{Na}$ in ethanol); and $50 \%$ sample solution $+50 \%$ ethanol (blank). The SDA plots were constructed with the $\mathrm{Na} / \mathrm{Li}$ emission intensity ratio on the $y$-axis versus $1 /[\mathrm{Li}]$ on the $x$-axis. For analysis of milk, bovine liver and mussel tissue CRMs, ethanol was replaced by water as solvent.
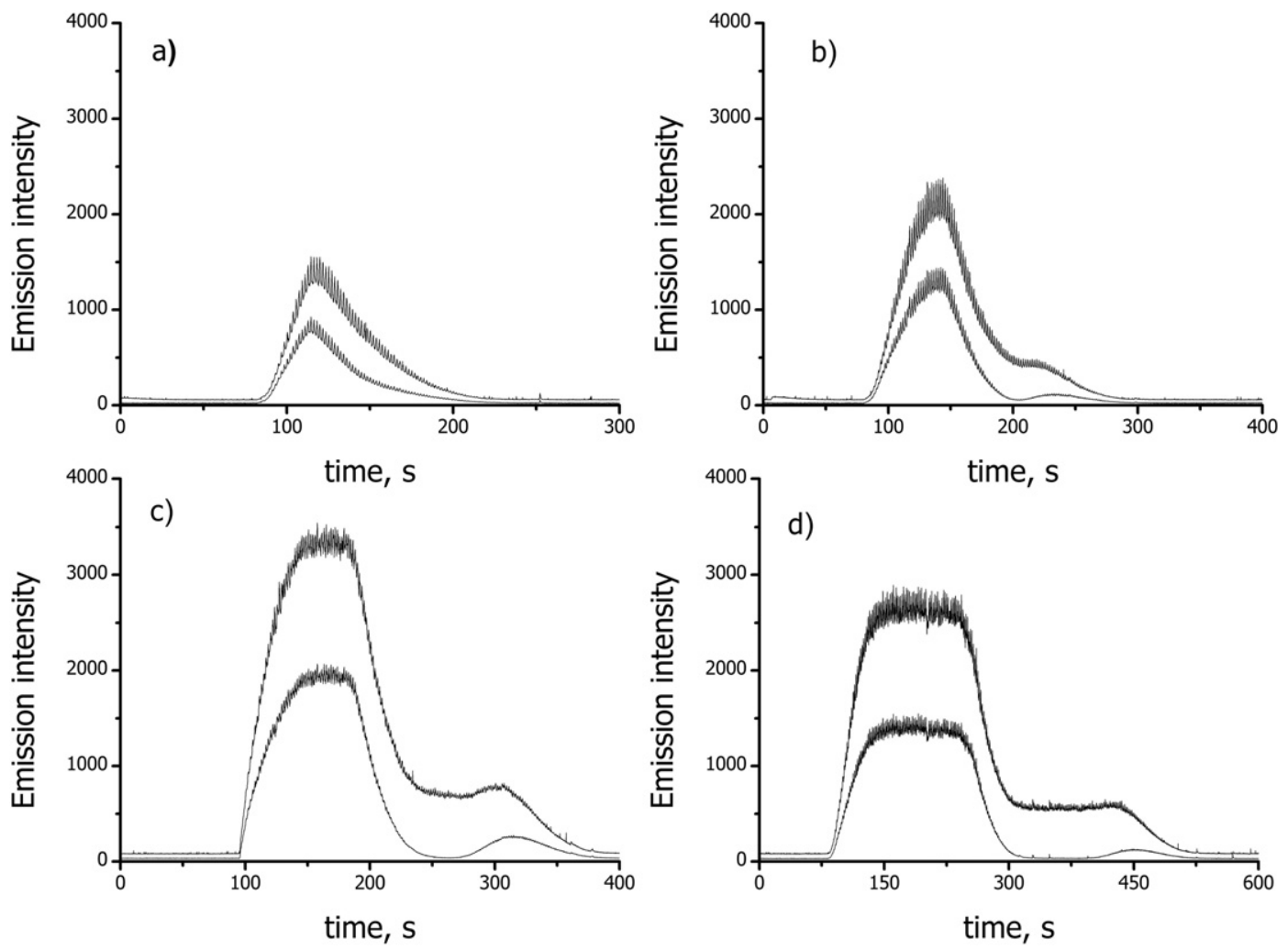

Fig. 3. Influence of sample loop volume. Signals for Na and Li were obtained with the system in Fig. 1 using $\mathrm{L}_{1}$ and $\mathrm{L}_{2}=0.5 \mathrm{~mL}$ (a), $1.0 \mathrm{~mL}$ (b), $1.5 \mathrm{~mL}$ (c) and $2.5 \mathrm{~mL}$ (d). 


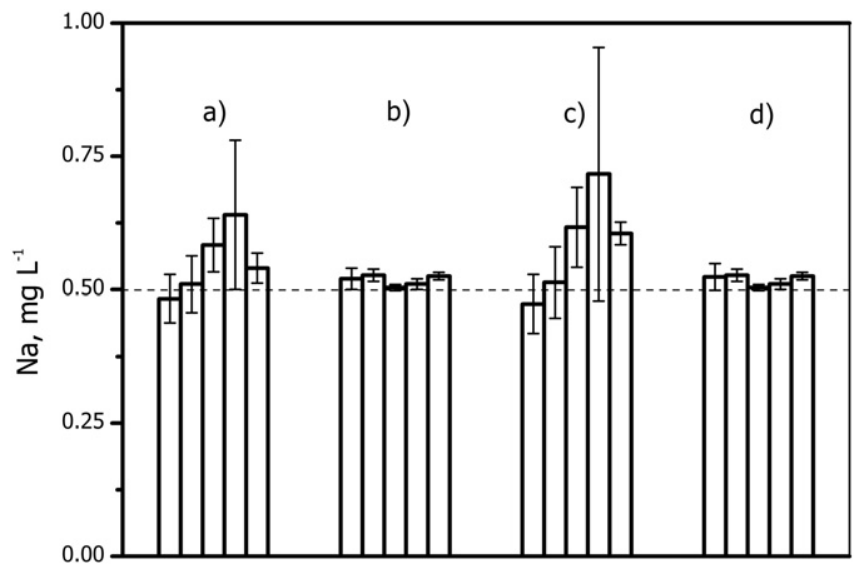

Fig. 4. Influence of sub-region of SDA curve on sodium determination. Five bars correspond to five samples analyzed by the SDA FIA using the following sub-regions of the SDA curve: $100-0 \%$ (a), $90-10 \%$ (b), $90-0 \%$ (c) and 100-10\% (d). Samples: spike solution of $0.5 \mathrm{mg} \mathrm{L}^{-1} \mathrm{Na}$. Blank: deionized water. Standard solution: $1.0 \mathrm{mg} \mathrm{L}^{-1}$ $\mathrm{Na}+1.0 \mathrm{mg} \mathrm{L}^{-1} \mathrm{Li}$.

External standard calibration curves were built up by plotting I ${ }^{\mathrm{Na}}$ versus [Na] for analytical solutions in the $0.1-1.0 \mathrm{mg} \mathrm{L}^{-1}$ range.

For IS calibration, all blanks, analytical solutions $\left(0.1-1.0 \mathrm{mg} \mathrm{L}^{-1} \mathrm{Na}\right)$ and samples were spiked with $0.5 \mathrm{mg} \mathrm{L}^{-1}$ Li. Calibration curves were built up by plotting $\mathrm{I}^{\mathrm{Na}} / \mathrm{I}^{\mathrm{Li}}$ versus [Na].

The SA calibration curves were built up by plotting I ${ }^{\mathrm{Na}}$ versus [Na] for spikes at final concentrations of 0.0 ("unspiked"), 0.1, 0.2, 0.3, 0.4 and $0.5 \mathrm{mg} \mathrm{L}^{-1} \mathrm{Na}$ in $10 \%\left(\mathrm{~m} \mathrm{v}^{-1}\right)$ of biodiesel.

Accuracy and precision were also evaluated by means of addition and recovery tests for biodiesel samples spiked with $0.2 \mathrm{mg} \mathrm{L}^{-1} \mathrm{Na}$.
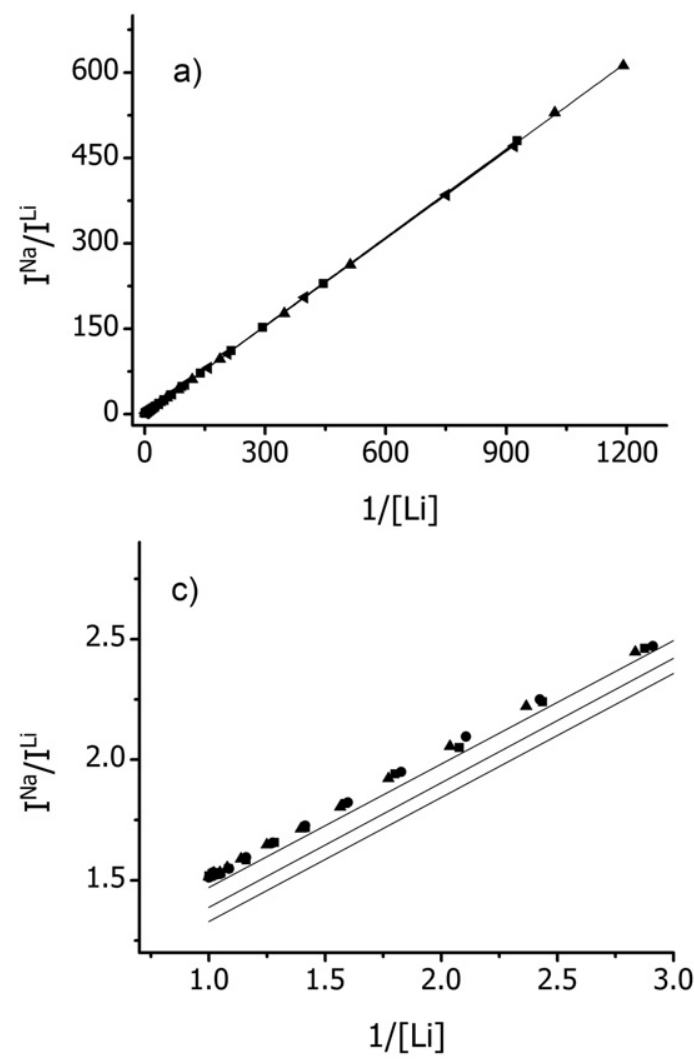

\section{Results and discussion}

\subsection{Optimization of the flow system}

The flow system depicted in Fig. 1 was designed to obtain limited dispersion [13]. Initially, the coiled tube $\left(B_{1}\right)$ was $110 \mathrm{~cm}$, the shortest length of tubing connecting the IC to the flame of spectrometer, avoiding a rigid arrangement of the flow setup. The flow-rate of the car-

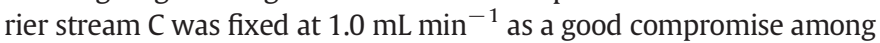
analytical frequency, overpressure and establishment of a welldefined SDA region. Considering that the nebulization chamber of the flame spectrometer may act as a diluting chamber [14,15], and that limited dispersion can be obtained in single-channel systems by increasing the sampling loop [13], the influence of the injected sample volume on signal profiles was evaluated in the $0.5-2.5 \mathrm{~mL}$ interval.

When the injected volume was lower than $1.0 \mathrm{~mL}$, only transitional signals were observed (Fig. 3a and b). A well-defined plateau region (steady-state signals) for $\mathrm{Na}$ and $\mathrm{Li}$ was observed for volumes of $\mathrm{L}_{1}$ and $\mathrm{L}_{2} \geq 1.5 \mathrm{~mL}$ (Fig. $3 \mathrm{c}$ and d). Although higher volumes decrease the sampling rate, the sampling loops corresponding to $2.5 \mathrm{~mL}$ were chosen for further studies since the main purpose here was illustrate the SDA in FIA system, not increase the sample throughput.

\subsection{Optimization of SDA}

A full signal record of one analytical cycle requires 6000 spectra, from which ca. 1000 spectra correspond to the SDA region. Considering the excessive number of spectra, the use of average spectra after 10-50 successive measurements was then evaluated. The variation in the number of average spectra $(100-20)$ interval did not alter significantly the results. So, the use of 30 spectra to calculate an average spectrum was chosen for further studies.

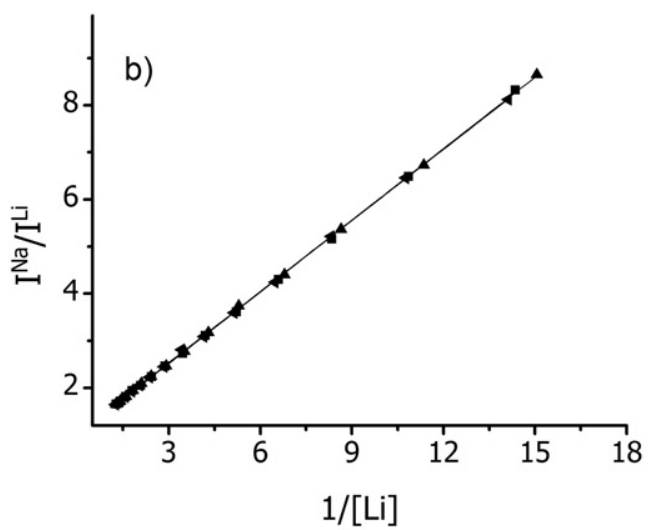

d)

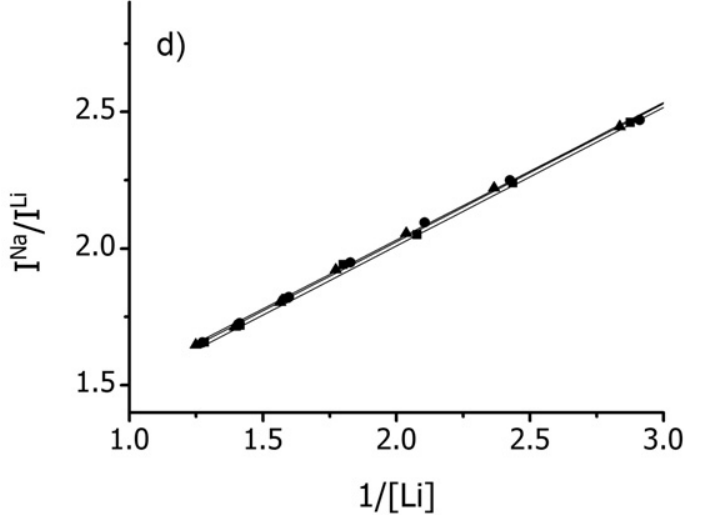

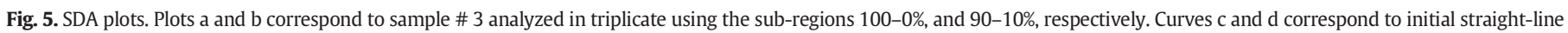
portion of the plots a and b extended, respectively. 
Table 1

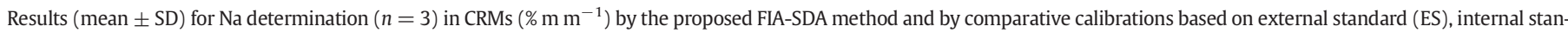
dardization (IS) and standard addition (SA).

\begin{tabular}{|c|c|c|c|c|c|}
\hline \multirow[t]{2}{*}{ CRM } & \multirow[t]{2}{*}{ Certified values } & \multicolumn{4}{|l|}{ Found values } \\
\hline & & FIA-SDA & ES & IS & SA \\
\hline Biodiesel & $2.5^{\mathrm{a}}$ & $2.5 \pm 0.2^{\mathrm{a}}$ & $5,7 \pm 0.3^{a}$ & $1.9 \pm 0.1^{\mathrm{a}}$ & $2.7 \pm 0.3^{\mathrm{a}}$ \\
\hline Bovine liver & $0.242 \pm 0.006$ & $0.241 \pm 0.009$ & $0.253 \pm 0.010$ & $0.244 \pm 0.011$ & $0.249 \pm 0.019$ \\
\hline Mussel tissue & $3.5 \pm 0.1$ & $3.5 \pm 0.1$ & $3.6 \pm 0.3$ & $3.5 \pm 0.2$ & $3.4 \pm 0.1$ \\
\hline Non fat milk & $0.497 \pm 0.010$ & $0.498 \pm 0.010$ & $0.576 \pm 0.040$ & $0.528 \pm 0.020$ & $0.532 \pm 0.060$ \\
\hline Whole milk & $0.356 \pm 0.040$ & $0.365 \pm 0.020$ & $0.430 \pm 0.020$ & $0.0402 \pm 0.020$ & $0.363 \pm 0.014$ \\
\hline
\end{tabular}

a Values expressed as $\mathrm{mg} \mathrm{kg}^{-1}$.

The influence of selection of sets of points at different parts of the SDA region was evaluated at the following four sub-regions: $100-0 \%$ (all points, Fig. 4a), 90-10\% (Fig. 4b), 90-0\% (Fig. 4c) and 100-10\% (Fig. 4d). These studies were carried out with $0.5 \mathrm{mg} \mathrm{L}^{-1} \mathrm{Na}$ sample solution, deionized water (blank) and $1.0 \mathrm{mg} \mathrm{L}^{-1} \mathrm{Na}+1.0 \mathrm{mg} \mathrm{L}^{-1} \mathrm{Li}$ (standard solution). Analysis of Fig. 4 reveals that better precision (typically $2 \%$ ) and more accurate results for five samples were obtained for sub-regions comprised in the ranges of $90-10 \%$ (Fig. 4b) and 100-10\% (Fig. 4d). The low emission intensities corresponding to final points (low Li concentration) contribute to deteriorate the quality of data. The lower the Li concentration, the higher the $\mathrm{I}^{\mathrm{Na}} / \mathrm{I}^{\mathrm{Li}}$ and $1 /[\mathrm{Li}]$ terms, deteriorating the lower limit of linear response of SDA plots. Fig. 5 correspond to SDA plots of the sample \# 3 analyzed in triplicate using the sub-regions $100-0 \%$ (Fig. 5a) and $90-10 \%$ (Fig. 5b). Slopes of curves for the triplicate were similar (sub-region 100-0\%: 0.5164, 0.5142 and 0.5117; sub-region $90-10 \%$ : $0.5065,0.5054$ and 0.5032 ). However, the situation changed by expanding the initial part of curves (Fig. $5 \mathrm{a}$ and b), showing those higher values have significant influence on trend line and $\mathrm{Y}$ intercept $(0.8716,0.8153$ and 0.9591$)$. When only the central points were used (Fig. 5d), that was not observed (Y intercept: 0.9967, 1.0139 and 1.0249). These findings suggest better results can be obtained when final points were eliminated. Thus, the sub-regions $90-10 \%$ or $100-10 \%$ can be employed for FIA-SDA calibration.

\subsection{Sodium determination}

After the FIA-SDA system optimization, accuracy was checked by analyzing five CRMs and the results for Na determination (Table 1) were in agreement with certified values at $95 \%$ confidence level ( $t$-test). In addition, Na was also determined by using ES, IS and SA as comparative

Table 2

Results (mean $\pm \mathrm{SD}$ ) for Na determination $(n=3)$ in biodiesel samples $\left(\mathrm{mg} \mathrm{kg}^{-1}\right)$ by the proposed FIA-SDA method and by comparative calibrations based on external standard (ES), internal standardization (IS) and standard addition (SA).

\begin{tabular}{lllll}
\hline Sample & FIA-SDA & ES & IS & SA \\
\hline B1 & $0.75 \pm 0.07$ & $1.40 \pm 0.04$ & $0.40 \pm 0.02$ & $0.92 \pm 0.10$ \\
B2 & $1.23 \pm 0.10$ & $1.97 \pm 0.15$ & $0.61 \pm 0.06$ & $1.54 \pm 0.26$ \\
B3 & $0.74 \pm 0.01$ & $1.50 \pm 0.07$ & $0.44 \pm 0.02$ & $0.90 \pm 0.03$ \\
B4 & $0.56 \pm 0.04$ & $1.10 \pm 0.06$ & $0.30 \pm 0.02$ & $0.65 \pm 0.06$ \\
B5 & $1.21 \pm 0.11$ & $2.04 \pm 0.04$ & $0.63 \pm 0.03$ & $1.25 \pm 0.13$ \\
\hline
\end{tabular}

Table 3

Recoveries in $\%$ (mean $\pm \mathrm{SD}$ ) of $0.2 \mathrm{mg} \mathrm{L}^{-1} \mathrm{Na}$ determined $(n=3$ ) by the FIA-SDA system and by comparative calibrations based on external standard (ES), internal standardization (IS) and standard addition (SA).

\begin{tabular}{lllll}
\hline Sample & FIA-SDA & ES & IS & SA \\
\hline nnn & $98 \pm 5$ & $202 \pm 17$ & $72 \pm 6$ & $119 \pm 10$ \\
B2 & $97 \pm 6$ & $181 \pm 8$ & $67 \pm 1$ & $111 \pm 9$ \\
B3 & $94 \pm 2$ & $191 \pm 15$ & $67 \pm 2$ & $126 \pm 11$ \\
B4 & $94 \pm 3$ & $198 \pm 17$ & $72 \pm 8$ & $113 \pm 7$ \\
B5 & $96 \pm 3$ & $194 \pm 14$ & $70 \pm 2$ & $117 \pm 10$ \\
\hline
\end{tabular}

calibration methods. The results obtained for $\mathrm{Na}$ in biodiesel and whole milk powder using ES did not agree with certified values at 95\% confidence level ( $t$-test). The content of $\mathrm{Na}$ in biodiesel was ca. 2.3 times higher than the certified value. This may be attributed to the increase in flame temperature caused by ethanol and reduced surface tension (increasing the nebulization of the sample and also the atomic population in flame) $[16,17]$. Unsatisfactory result for $\mathrm{Na}$ in biodiesel was also observed by using IS. The underestimated recovery (76\%) was probably caused by the different behavior of $\mathrm{Na}$ and Li concerning the increase in the flame temperature due to sample atomization. This effect can be related to different energy transitions relative to emission lines of $\mathrm{Na}(2.1044 \mathrm{eV})$ and $\mathrm{Li}(1.8478 \mathrm{eV})$ [18]. Results obtained for others CRMs were in agreement with the certified values at the $95 \%$ confidence level with the certified values. Regarding SA calibration, results for Na were in agreement with the certified values at the $95 \%$ confidence level ( $t$-test). Considering the SA method requires a series of standards, the proposed method needs only two solutions per analysis. The RSD calculated for the FIA-SDA and SA were $4.4 \%$ and $7.3 \%$, respectively.

The FIA-SDA system was also applied to the determination of $\mathrm{Na}$ in commercial biodiesel samples (Table 2). For comparison purposes, samples were also analyzed by using ES, IS and SA. Analysis of Table 2 reveals that only results for Na determination by the SA method were in agreement at the 95\% confidence level (paired $t$-test) with the results obtained by FIA-SDA. The RSD $(\mathrm{n}=3)$ calculated for samples were in the 1.3-9.3\% (FIA-SDA) and 3.3-16.9\% (SA) intervals.

The performance of the FIA-SDA system was also evaluated by addition and recovery tests in all samples (Table 3). Recoveries of Na were in the following ranges: 181-202\% (ES), 67-72\% (IS), 111-126\% (SA), and 94-98\% (FIA-SDA). These findings reinforce the efficacy of the proposed system described in this work.

\section{Conclusions}

It was demonstrated here the possibility of using SDA in a flow system. The proposed method combines the benefits of two classic methods (standard additions and internal standardization) with the convenience of preparing only two solutions per sample. The efficiency of SDA in flow system was demonstrated here for the determination of $\mathrm{Na}$ in biodiesel samples by atomic emission spectrometry, but it can be adapted to various analytes, samples and techniques. SDA requires the simultaneous measurement of both analyte and internal standard. The optical fiber probe coupled to flame AAS was employed in this work due to the unavailability of a simultaneous spectrometer in our laboratory. However, the FIA-SDA method can obviously be carried out in any commercial simultaneous instrument.

\section{Acknowledgements}

The authors thank the São Paulo Research Foundation - FAPESP for financially supporting this work (Project 2014/12595-1) and for fellowships to F.M.F. (2012/23323-7) and A.V. (2014/18393-1). The Conselho Nacional de Desenvolvimento Científico e Tecnológico CNPq is also thanked for financially supporting this work (Project 471453/2013-7) and fellowships to M.A.B. and researchship to J.A.G.N. 
(303255/2013-7). The Monitoring and Research Center for Fuel Quality, Biofuels, Oil and Derivatives (CEMPEQC) is thanked for providing biodiesel samples.

\section{References}

[1] D.A. Skoog, D.M. West, F.J. Holler, Fundamentals of analytical chemistry, 6th ed Saunders College Pub., Fort Worth, 1992 (892 p.)

[2] G.D. Christian, P.K. Dasgupta, K.A. Schug, Analytical chemistry, 7th ed Wiley, New York, 2014 (826 p.).

[3] L. Cuadros-Rodríguez, L. Gámiz-Gracia, E.M. Almansa-López, J.M. Bosque-Sendra, Calibration in chemical measurement processes. II. A methodological approach, Trends Anal. Chem. 20 (2001) 620-636.

[4] Z. Mester, R.E. Sturgeon, Sample preparation for trace element analysis, 1st ed. Elsevier, Boston, 2003 79-81.

[5] W.B. Barnett, V.A. Fassel, R.N. Kniseley, Theoretical principles of internal standardization in analytical emission spectroscopy, Spectrochim. Acta B 23 (1968) 643-664

[6] L.H.J. Lajunen, P. Perämäki, Spectrochemical analysis by atomic absorption and emission, 2nd ed Royal Society of Chemistry, Cambridge, 2004 (342 p.).

[7] W.B. Jones, G.L. Donati, C.P. Calloway Jr., B.T. Jones, Standard dilution analysis, Anal. Chem. 87 (2015) 2321-2327.

[8] E.A.G. Zagatto, C.C. Oliveira, A. Townshend, P.J. Worsfold, Flow analysis with spectrophotometric and luminometric detection, 1st ed Elsevier, Massachusetts, 2012 (472 p.).

[9] F.J. Feldman, Internal standardization in atomic emission and absorption spectrometry, Anal. Chem. 42 (1970) 719-724.
[10] M.R.L. Magalhães, A.I. Barros, A.P. Oliveira, A. Santos, Dissolution in ethanol as a sample preparation procedure for determination of metals in biodiesel by FAAS, Curr. Anal. Chem. 10 (2014) 166-171.

[11] E.S. Chaves, M.T.C. Loos-Vollebregt, A.J. Curtius, F. Vanhaecke, Determination of trace elements in biodiesel and vegetable oil by inductively coupled plasma optical emission spectrometry following alcohol dilution, Spectrochim. Acta B 66 (2011) 733-739.

[12] F.J. Krug, H. Bergamin Filho, E.A.G. Zagatto, Commutation in flow-injection analysis, Anal. Chim. Acta 179 (1986) 103-118.

[13] J. Ruzicka, E.H. Hansen, Flow injection analysis, 2nd ed Wiley, New York, 1988 (498 p.).

[14] J.A. Gomes Neto, J.B.B. Silva, R.R. Neto, A.J. Curtius, I.G. Souza, Emprego de nebulizador pneumático de ICP-MS como câmara de diluição em sistemas de injeção em fluxo para determinações multielementares, Quim. Nova 21 (1998) 405-409.

[15] I.L. García, P. Vinãs, M.H. Córdoba, Calibration in flame atomic absorption spectrometry using a single standard and gradient technique, J. Anal. At. Spectrom. 9 (1994) 553-561.

[16] F.R.P. Rocha, J.A. Nóbrega, Effects of Solution Physical Properties on Copper and Chromium Signals in Flame Atomic Absorption Spectrometry, J. Chem. Educ. 73 (1996) 982-984.

[17] K. Szivós, Application of organic solvents in atomic-absorption spectrophotometry, Period. Polytech., Chem. Eng. 25 (1981) 121-132.

[18] D.R. Lide (Ed.), CRC Handbook of Chemistry and Physics, 88th edCRC Press, Boca Raton, 2008 